\title{
Combining Diffusion Tensor Imaging and Susceptibility Weighted Imaging on the Substantia Nigra of 1-Methyl-4-Phenyl-1,2,3,6-Tetrahydropyridine (MPTP)-induced Rhesus Monkey Model of Parkinson's Disease
}

\author{
Q Zhang ${ }^{1}, \mathrm{~L} \mathrm{Li}^{2}$, B Miao ${ }^{3}, \mathrm{H} \mathrm{Niu}^{1}$
}

\begin{abstract}
Objective: The aim of this study was to evaluate whether combining diffusion tensor magnetic resonance imaging (DTI) and susceptibility weighted imaging (SWI) techniques would provide a sensitive method for differentiating between 1-methyl-4-phenyl-1,2,3,6-tetrahydropyridine (MPTP)-induced rhesus monkey model of Parkinson's disease (PD) and wild-type controls.

Subjects and Methods: Seventeen rhesus monkeys were divided into two groups. A series of intramuscular injections of either saline (control group, $n=8)$ or MPTP $(0.2 \mathrm{mg} / \mathrm{kg}$ body weight; PD group, $n=$ 9) were given to the monkeys, twice a week. Then, SWI and DTI scans were obtained from the monkeys with Siemens Magnetom Verio 3.0T superconductive MRI system. Region of interest analysis was performed on substantia nigra pars compacta ( $S N c)$ and substantia nigra pars reticulata (SNr). In addition, immunohistochemical staining of tyrosine hydroxylase was applied to assess degeneration of SN dopaminergic neurons.

Results: Monkeys in the PD group displayed mild to moderate motor symptoms assessed using Kurlan's scale. With SWI scans, decreased width of SNc but increased width of SNr was found in PD group monkeys compared to controls. Calculation of the ratios of widths of SNc and SNr to the anterior and posterior mesencephalic diameter also reflected narrower SNc but wider SNr than controls. Decreased SWI signal intensity of SNc and SNr suggested iron deposition in both subregions of SN. The DTI scans showed lower fractional anisotropy (FA) values in SNc of the PD group monkeys, while no change of FA values in $\mathrm{SNr}$ was detected. Immunohistochemical test displayed generalized loss of dopaminergic neurons in $S N$ of PD group monkeys.

Conclusion: Combining the use of DTI and SWI can provide a sensitive method for differentiating between MPTP-induced rhesus monkey model of PD and wild-type controls. This effective imaging modality might provide additional information for characteristic identification of PD at early stages, thus enhancing the ability to make early diagnosis, and monitor progression of the natural history and treatment effects.
\end{abstract}

Keywords: Diffusion tensor imaging, Parkinson's disease, susceptibility weighted imaging

\section{Combinación de Imágenes con Tensor de Difusión e Imágenes de Susceptibilidad Magnética Ponderada de la Sustancia Negra en un Modelo de la Enfermedad de Parkinson Inducida Mediante 1-Metil-4-Fenil-1,2,3,6- Tetrahidropiridina (MPTP) en Monos Rhesus}

Q Zhang ${ }^{1}, \mathrm{~L} \mathrm{Li}^{2}, \mathrm{~B} \mathrm{Miao}{ }^{3}, \mathrm{H} \mathrm{Niu}^{1}$

\begin{abstract}
RESUMEN
Objetivo: El objetivo de este estudio fue evaluar si las técnicas de imagen por resonancia magnética con tensores de difusión (ITD) combinadas con las de imagen por susceptibilidad magnética ponderada (ISP), proporcionarían un método sensible para diferenciar entre el modelo de la enfermedad de
\end{abstract}

From: ${ }^{1}$ Department of Genetics, Xuzhou Medical College, Xuzhou 221004, China, ${ }^{2}$ Department of Radiation Medicine, Chengdu Military General Hospital, Chengdu 610000, China and ${ }^{3}$ Jiangsu Province Key Laboratory of Anaesthesiology, Xuzhou Medical College, Xuzhou 221004, China.
Correspondence: Q Zhang, Department of Genetics, Xuzhou Medical College, Xuzhou 221004, China. E-mail: shoutian@163.com 
Parkinson (EP) inducida mediante 1-metil-4-fenil-1,2,3,6-tetrahidropiridina (MPTP) en monos rhesus y los controles de tipo salvaje.

Sujetos y Métodos: Diecisietes monos rhesus fueron divididos en dos grupos. Dos veces por semana, los monos recibieron inyecciones intramusculares, bien de solución salina (grupo control, $n=8$ ), o MPTP $(0.2 \mathrm{mg} / \mathrm{kg}$ por peso corporal; grupo EP, $n=9)$. Entonces, se obtuvieron escaneos por ISP y ITD de los monos, usando un sistema superconductor IRM Siemens Magnetom Verio 3.0 T. Se realizó un análisis ROI (región de interés) de la sustancia negra pars compacta ( $S N c)$ y de la sustancia negra pars reticulata (SNr). Además, se aplicó la coloración inmunohistoquímica de la tirosina hidroxilasa con el propósito de evaluar la degeneración de las neuronas dopaminérgicas de la SN.

Resultados: Los monos en el grupo EP mostraron sintomas motores de leves a moderados, evaluados según la escala de Kurlan. En el análisis con ISP, se halló una disminución del ancho de la SNc, pero un aumento de ancho de la SNr en los monos del grupo EP, en comparación con los controles. El cálculo de los cocientes de las anchuras de la SNc y la SNr en relación con el diámetro mesencefálico anterior y posterior, también reflejó una SNc más estrecha pero una SNr más amplia que las de los controles. La disminución de la intensidad de la señal ISP de la SNc y la SNr sugiere depósito de hierro en ambas subregiones de la SN. Los escaneos de ITD mostraron valores de anisotropía fraccional (FA) más bajos en la SNc de los monos del grupo EP, mientras que no se detectaron cambios en los valores FA en la SNr. La prueba inmunohistoquímica mostró una pérdida generalizada de las neuronas dopaminérgicas en la $S N$ de los monos del grupo con EP.

Conclusión: Combinar el uso de ITD e ISP puede proporcionar un método sensible para diferenciar entre el modelo de la enfermedad de Parkinson (EP) inducida por MPTP en monos rhesus y los controles de tipo salvaje. Esta modalidad efectiva de obtención de imágenes puede proporcionar información adicional para la identificación de características de la EP en etapas tempranas, aumentando así la capacidad para hacer un diagnóstico precoz y monitorear el progreso de la historia natural y los efectos del tratamiento.

Palabras claves: Imagen con tensores de difusión, enfermedad de Parkinson, imagen por susceptibilidad magnética ponderada

West Indian Med J 2015; 64 (5): 481

\section{INTRODUCTION}

Parkinson's disease (PD) is a common and complex neurodegenerative disorder with diagnostic characteristics of rigidity, resting tremor, bradykinesia and postural instability. The main pathological changes of PD include dopaminergic neuronal loss in the substantia nigra (SN), micro- and astro-gliosis and intraneuronal cytoplasmic inclusions called "Lewy bodies". Clinically, a diagnosis of PD can commonly be made in the early to later stages with major loss of SN neurons and their destroyed terminals (1). In addition to misdiagnosis owing to limited early detection, neuroprotective treatments which are considered to be promising future PD therapy also require early diagnosis, when it is still eligible for patients to stop the neurodegenerative process (2). In this regard, reliable surrogate markers for identifying early stages of PD are urgently needed, not only for the diagnosis, but also for evaluating efficacy and monitoring disease modification effects during the therapy.

Conventional magnetic resonance imaging (MRI) of PD patients shows few differences compared to healthy individuals. There may be slight volumetric changes, especially in the SN (3). Recently, new imaging techniques such as susceptibility weighted imaging (SWI) and diffusion tensor magnetic resonance imaging (DTI) have been applied to PD patients to improve understanding of pathophysiologic changes (4). The SWI technique is mainly based on a natural property of tissues
- magnetic susceptibility effects, which reflects the magnetic response of a substance in an external magnetic field. The ferromagnetic substances, such as iron, exhibiting a strong susceptibility effect can be detected with SWI more easily. Therefore, SWI is usually adopted to assess iron deposition in cerebral nuclei in some neurodegenerative disorders, including Alzheimer's, Huntington's and Parkinson's diseases (5). Diffusion tensor imaging can assess the diffusion of water molecules, allowing non-invasive in vivo display of neuronal microstructure by mapping water proton motion within the tissue microenvironment (6), and it has been used to detect degeneration of nigrostriatal fibres and to reveal alterations of white matter in PD patients $(7,8)$. However, the stability and reliability in providing candidate diagnostic biomarkers for early PD diagnosis with single usage of DTI or SWI remain controversial.

As such, we wondered whether there would be an effective way for application of combining SWI and DTI in PD diagnosis at comparatively early stages, and whether the visual neuroimaging characteristics could be in concordance with underlying pathological alterations. Thus, we employed a chronic 1-methyl-4-phenyl-1,2,3,6-tetrahydropyridine (MPTP) treated monkey model of PD, which displayed gradual development of nigral and striatal lesions, most closely mimicking the typical PD progression in humans (9). We per- 
formed SWI and DTI scans on PD monkeys and wild-type controls, focussing on the width alterations of substantia nigra pars compacta $(\mathrm{SNc})$ as well as substantia nigra pars reticulata (SNr) with SWI, and on the fractional anisotropy (FA) changes in these areas with DTI. The immunochemical tests were intended to verify SN lesions and to provide a reasonable explanation for the neuroimaging signatures.

\section{SUBJECTS AND METHODS Animals}

Seventeen male adult rhesus monkeys (Macaca mulatta, 7-9 $\mathrm{kg}$ ) from Kunming Primate Research Centre of Chinese Academy of Science were used in this study, in accordance with the National Institutes of Health Guidelines for the Care and Use of Laboratory Animals. All procedures were approved by the Animal Care and Use Committee at Kunming Medical College. The monkeys were housed in a temperature-controlled room with an alternating 12/12-hour light/dark cycle. They were fed with monkey chow supplemented with vegetables and fruits twice daily. The animals had free access to water.

\section{MPTP administration and behavioural evaluation}

These 17 monkeys were divided into two groups. A series of intramuscular injections of either saline (control group, $\mathrm{n}=8$ ) or MPTP $(0.2 \mathrm{mg} / \mathrm{kg}$ body weight; Sigma-Aldrich, St Louis, MO, USA; PD groups, $n=9$ ) were given to the monkeys, twice a week. The animals were continuously monitored in their home cages using a digital video recorder. To obtain monkeys' PD scores and determine the severity of parkinsonism, motor dysfunctions were assessed using Kurlan's scale proposed by Kurlan (10). Briefly, the monkeys' behaviours were evaluated and scored from 0 to 2 or 4 with a total score of 20 by two experienced raters in the following categories: tremor, rigidity, posture, bradykinesia, balance, arm movements and defence reaction.

\section{Instrument}

The Siemens Magnetom Verio 3.0T superconductive MRI system (Siemens, Erlangen, Germany) was used. Study animals were anesthetized using sodium pentobarbital $(20 \mathrm{mg} / \mathrm{kg})$ and monitored to maintain constant physiological parameters. The monkeys were put to lie on their backs and tested with an eightchannel Head Matrix fixed to the head. The animal's head was positioned in the midline between both shoulders. Cushions were used to help to maintain the head position.

\section{SWI data acquisition and preprocessing}

Susceptibility weighted imaging used 3D gradient-echo sequence with parameters as follows: TR $30.0 \mathrm{~ms}$, TE $20.0 \mathrm{~ms}$, flip angle $15^{\circ}$, bandwidth $120 \mathrm{~Hz}$, field of view $120 \times 78 \mathrm{~mm}^{2}$, 52 slices, slice thickness $1.0 \mathrm{~mm}$, slice spacing $0.2 \mathrm{~mm}$, matrix size $256 \times 256$. Post image processing was performed on Siemens Workstation after data acquisition with SWI scan. All images were read by two experienced radiologists who manually measured widths of $\mathrm{SNc}, \mathrm{SNr}$ and the anteroposterior di- ameter of the midbrain. They also marked the region of interest (ROI), which included $\mathrm{SNc}$ and $\mathrm{SNr}$ in three slices where they were best observed. The signal intensity of SNc and $\mathrm{SNr}$ were given automatically by Siemens Workstation. The radiologists were blinded to the monkeys' grouping.

\section{DTI data acquisition and preprocessing}

Diffusion tensor imaging covering the whole brain in axial slices: TR $6200 \mathrm{~ms}$, TE $97 \mathrm{~ms}$, bandwidth $1526 \mathrm{~Hz}$, field of view $137 \times 137 \mathrm{~mm}^{2}$, matrix size $256 \times 256 ; \mathrm{b}=0 \mathrm{~s} / \mathrm{mm}^{2}$; number of gradients $8 ; 36$ slices; slice thickness $1.6 \mathrm{~mm}$; no gaps. Data were processed with MRIcro, followed by eddy current correction with DTIstudio. Regions of interest which included $\mathrm{SNc}$ and $\mathrm{SNr}$ were manually marked by two experienced radiologists, and the FA values were prepared for analysis.

\section{Immunohistochemistry}

Animals were sedated with ketamine hydrochloric acid (10 $\mathrm{mg} / \mathrm{kg}$, intramuscular) and then deeply anaesthetized with sodium pentobarbital (30 mg/kg, intravenous). The monkeys were then transcardially perfused with $0.9 \%$ saline followed by a fixative that comprised $4 \%$ PFA in $0.01 \mathrm{M}$ phosphatebuffered saline (PBS, $\mathrm{pH}=7.4$ ). The brains were removed and then located in 10, 20 and $30 \%$ sucrose - $0.01 \mathrm{M}$ PBS to completely dehydrate the tissues. Coronal frozen section of the brains were at $20 \mu \mathrm{m}$ thickness. After permeabilization and blocking, the frozen coronal sections were incubated with rabbit anti-tyrosine hydroxylase (TH) antibody (1:1000; Santa Cruz Biotechnology) overnight at $4{ }^{\circ} \mathrm{C}$. They were washed with $0.01 \mathrm{M}$ PBS buffer and incubated with biotinylated goat antirabbit antibody (1:200; vector Lab, CA, USA) for 20 minutes at $37{ }^{\circ} \mathrm{C}$. The streptovidin-conjugated horse radish peroxidase was then added, with 3, 39-diaminobenzidine (DAB) used as the chromagen (Vectastain Elite ABC Kit, Vector Laboratories, CA, USA). The sections were dehydrated through a graded ethanol series and coverslipped with resinene. The sections were examined under a $40 \times$ objective lens magnification, and TH immunoreactivity was measured with ImagePro Plus software (Media Cybernetics, Silver Spring, USA).

\section{Statistical analysis}

Statistical analysis was performed with SPSS 13.0 software (SPSS Inc., Chicago, IL). Comparisons were performed using Student's $t$-test between the PD group and control group. Results are presented as means \pm SEM. A $p$-value $<0.05$ was considered to be a statistically significant difference.

\section{RESULTS}

\section{Behavioural effects of MPTP}

Currently, the primate model induced with the neurotoxin MPTP is considered as the gold standard animal model for PD because of its closest resemblance to PD in humans (9). The chronic low dose MPTP model of parkinsonism in non-human primates we adopted in this research was specifically devel- 
oped to study the presymptomatic motor state in early stage of PD (11). After intramuscular injection of MPTP $(0.2 \mathrm{mg} / \mathrm{kg}$ body weight) twice a week for 330 days, all monkeys in PD group displayed mild to moderate motor symptoms, with the highest score of 9 in Kurlan's scale. No signs of parkinsonism were detected in monkeys of the control group and their mean parkinsonian symptoms scores were 0 (Fig. 1). Daily records showed that the scores of monkeys in PD group gradually increased in the initial 150 days, and MPTP was close to reaching its maximum effect in the following days, suggesting the stable establishment of motor dysfunctions.

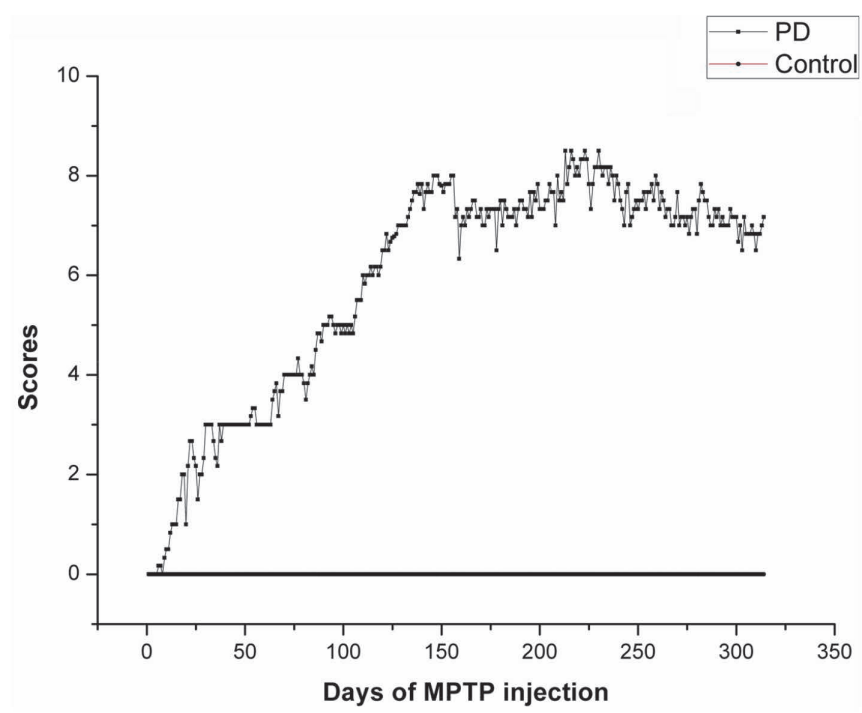

Fig. 1: Behavioural effects of 1-methyl-4-phenyl-1,2,3,6-tetrahydropyridine (MPTP) on rhesus monkeys. The mean parkinsonian symptom scores were significantly elevated in the Parkinson's disease (PD) group after intramuscular injection of MPTP $(0.2 \mathrm{mg} / \mathrm{kg}$ body weight) twice a week. Scores of the control group remained at zero.

\section{SWI scans}

Though iron deposition of SN in PD patients has been detected on SWI, there is still lack of accurate subregional position of the SN involved. There have been scarce reports about the anatomic characteristics of $\mathrm{SNc}$ and $\mathrm{SNr}$ during PD process on SWI. So firstly, we focussed on signal intensity of SNc and $\mathrm{SNr}$, respectively, which could reveal iron depositon of each part. On the images clearly showing SN (Fig. 2), we marked SNc and SNr for the ROIs (Fig. 3), and read their signal intensity. Our results showed that $\mathrm{SNc}$ and $\mathrm{SNr}$ of PD monkeys had lower signal intensity than controls (Fig. 4), reflecting iron depositon of both parts of SN in PD group monkeys. Then we measured the widths of SNc and SNr (Fig. 5), finding decreased width of SNc but increased width of SNr compared to controls (Fig. 6A). Furthermore, to reduce statistical outliers, we also measured the anterior and posterior mesencephalic diameter and calculated the ratios of widths of $\mathrm{SNc}$ and $\mathrm{SNr}$ to it (Fig. 5), finding the same anatomic changes of $\mathrm{SNc}$ and $\mathrm{SNr}$ in PD monkeys (Fig. 6B).

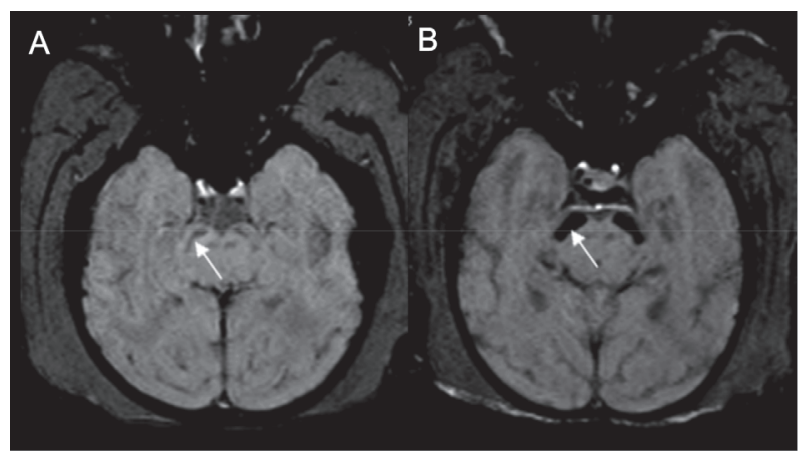

Fig. 2: Susceptibility weighted imaging clearly showing substantia nigra (SN). A: images of control group monkeys; B: images of Parkinson's disease group monkeys. White arrow indicates the SN.

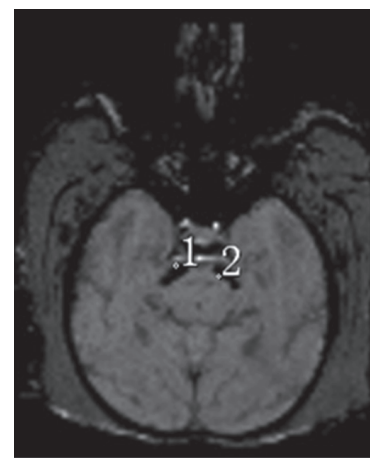

Fig. 3: Regions of interest in susceptibility weighted images. ' 1 ' indicates substantia nigra pars reticulata and ' 2 ' indicates substantia nigra pars compacta.

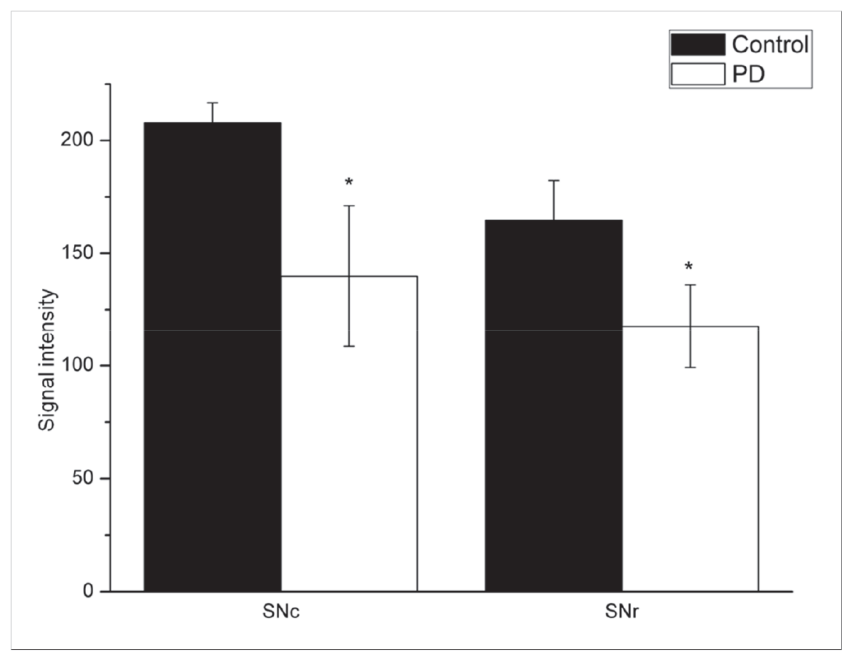

Fig. 4: Signal intensity of substantia nigra pars compacta (SNc) and substantia nigra pars reticulata (SNr). Both SNc and $\mathrm{SNr}$ of Parkinson's disease (PD) monkeys had lower signal intensity than controls $\left({ }^{*} p<\right.$ 0.05 ). 


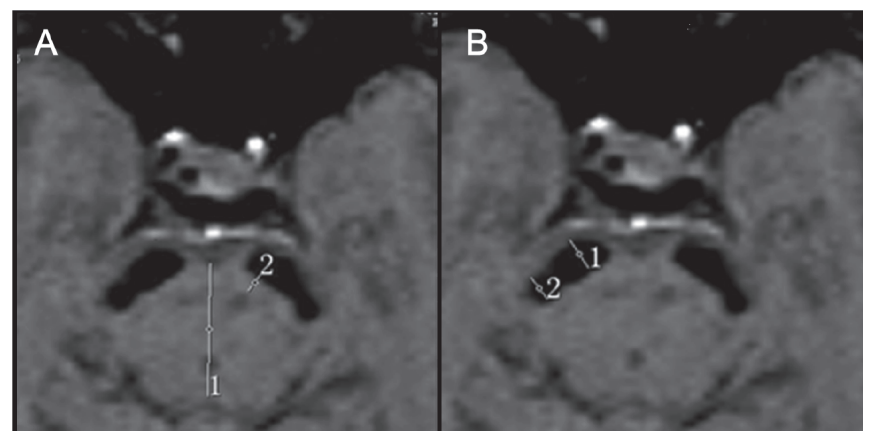

Fig. 5: Measurements of the widths of subtantia nigra pars compacta (SNc) and substantia nigra pars reticulata (SNr). A: ' 1 ' indicates the anterior and posterior mesencephalic diameter; ' 2 ' indicates the width of SNc. B: 1 indicates the width of anterior $\mathrm{SNr}$, and 2 indicates the width of posterior $\mathrm{SNr}$; the average value of 1 and 2 was used as the width of SNr.
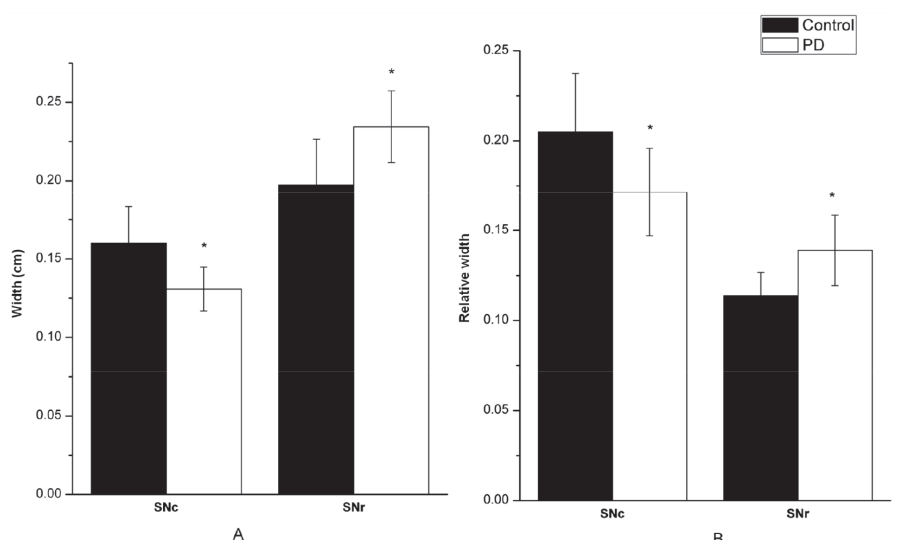

Fig. 6: A: the widths of subtantia nigra pars compacta ( $\mathrm{SNc}$ ) and substantia nigra pars reticulata $(\mathrm{SNr}) \mathrm{B}$ : the ratios of widths of $\mathrm{SNc}$ and $\mathrm{SNr}$ to the anterior and posterior mesencephalic diameter. Decreased width of SNc but increased width of $\mathrm{SNr}$ compared to controls was found $\left({ }^{*} p<0.05\right)$

\section{DTI scans}

In order to investigate the microstructure integrity of SNc and SNr, we carried out DTI scans on the PD monkeys and controls. After acquisition of DTI images with clear observation of the SN, ROIs including SNc and SNr were marked (Fig. 7), according to the methods described before (12), then FA was measured in ROIs. We found that SNc showed decreased FA values in the PD group than controls, while no significant differences were detected within $\mathrm{SNr}$ of the PD monkeys compared to controls (Fig. 8).

\section{MPTP induced generous loss of TH positive neurons in SN of PD monkeys}

Recent studies have suggested that MPTP-induced non-human primate animal model of parkinsonism proved to be a valuable tool in mimicking the pathological features of PD and developing new neuroprotective strategies $(13,14)$. In order to confirm the pathological alterations of SN in PD monkeys, and to examine whether the neuroimaging abnormalities coincide with them, immunohistochemical staining of tyrosine hydroxy-

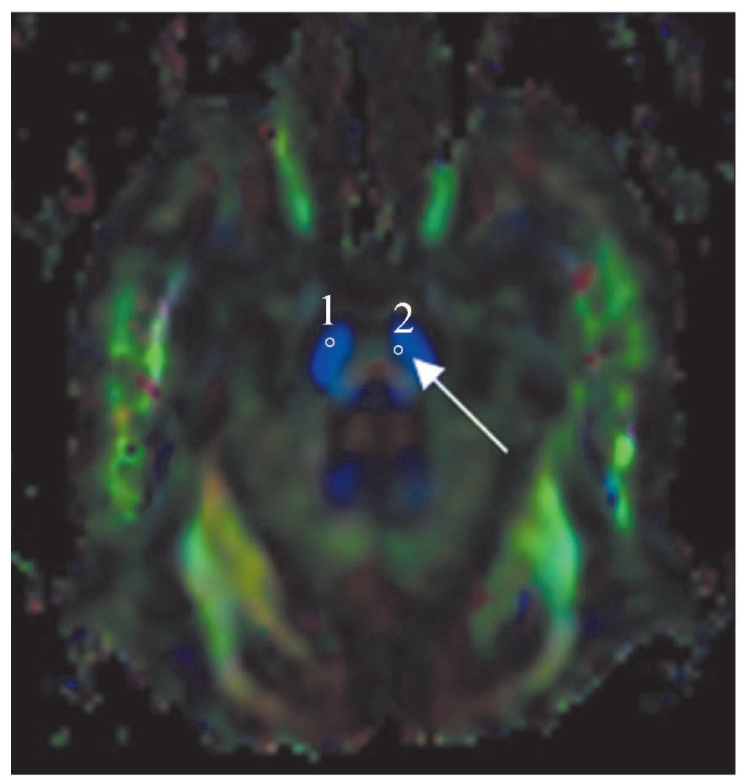

Fig. 7: Regions of interest in diffusion tensor images. White arrow indicates the substantia nigra. ' 1 ' indicates substantia nigra pars reticulata $(\mathrm{SNr})$ and '2' indicates subtantia nigra pars compacta $(\mathrm{SNc})$.

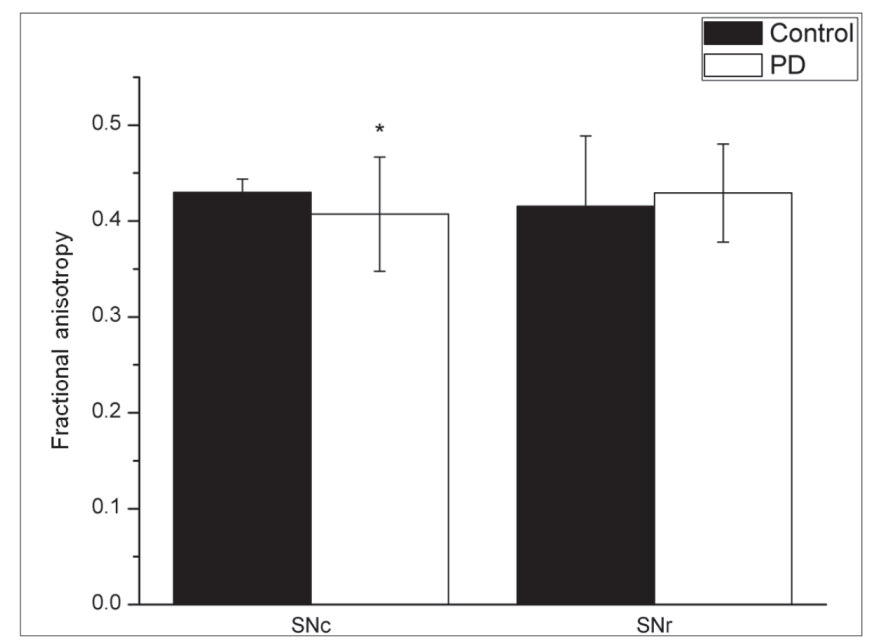

Fig. 8: Fractional anisotropy values of substantia nigra pars compacta (SNc) in the Parkinson's disease (PD) group were lower than controls. No significant differences were detected within substantia nigra pars reticulata $(\mathrm{SNr})$ of the $\mathrm{PD}$ monkeys compared to controls $\left({ }^{*} p<0.05\right)$.

lase (TH) was applied to assess the degeneration of SN dopaminergic neurons. In comparison with control group monkeys, administration of MPTP caused a marked reduction in number of $\mathrm{TH}+$ dopaminergic neurons in the $\mathrm{SN}(36.17 \pm 4.08$ in control group, $107.83 \pm 7.89$ in PD group; $p<0.001)$. The boundary of SN and its subregions also became dispersed (Fig. 9). These results demonstrated that typical pathological features of PD had been successfully induced with MPTP in PD group monkeys. 


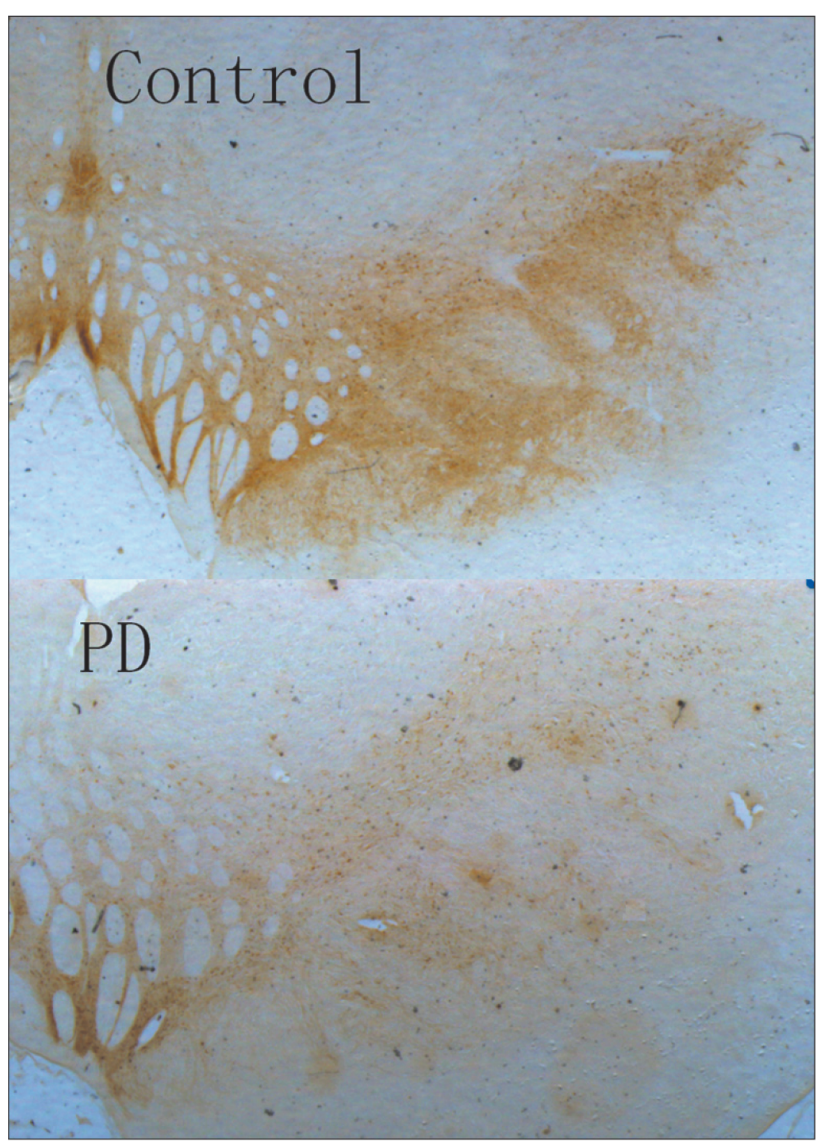

Fig. 9: Immunohistochemical staining of tyrosine hydroxylase (TH) shows degeneration of substantia nigra (SN) dopaminergic neurons in Parkinson's disease (PD) group monkeys. The boundary of SN and its subregions also became dispersed.

\section{DISCUSSION}

As a movement disorder, mainly related to dopamine insufficiency in the brain, Parkinson's disease affects at least 10 million people worldwide, and it is one of the most complicated neurodegenerative diseases, causing a broad spectrum of motor and non-motor symptoms (15). There are growing data supporting relatively new (MRI) techniques used in the diagnosis of PD as well as monitoring the progression of PD pathogenesis, such as DTI, SWI and functional imaging $(16,17)$. However, a single advanced MRI technique might be insufficient to effectively detect early PD patients; integration of different unconventional MRI methods was proposed for identification of the pathological changes at a relatively early stage of PD with enhanced accuracy (18).

So far, the anatomic characteristics of $\mathrm{SNc}$ and $\mathrm{SNr}$ at early stages of PD on neuroimaging are not fully confirmed. Previous literature has demonstrated that narrowing or disappearance of SNc can be uncommonly seen on T2 weightedimaging of conventional MRI (19), but with low sensitivity and specificity, thus contributing marginally to PD diagnosis, particularly at an early stage. On account of the iron deposition of SN in PD status, we expect the high sensitivity of SWI to show magnetic susceptible tissues can be helpful in depicting $\mathrm{SN}$ and substructures more clearly. Our results indicated that widened $\mathrm{SNr}$ and narrowed SNc were detected on SWI images, which might be specific anatomic characteristics of SN in MPTP-treated monkeys. These neuroimaging changes might result from degradation of neurons in $\mathrm{SNc}$, which is marked in the degenerative pathogenesis of PD. Though several previous studies used SWI to assess brain iron deposition in PD, the results still can hardly provide solid characteristic features for identification of PD, especially at an early stage. Besides, the part of SN which was chosen as the ROI was rarely described. Therefore, we assessed the signal intensity of $\mathrm{SNc}$ and SNr, respectively, in this study. The results demonstrated hypointensity of both parts of SN in the PD group, which might correlate largely, if not perfectly, with the deposition of iron in these regions at an early stage of PD. Our research suggests that the combined assessment of widths and signal intensity for the two parts of SN can reflect some characteristic features for identification of PD at early stages, or at least provide supplementary information for other diagnostic work-up.

Diffusion tensor imaging, as a measure of local water diffusivity and microstructure integrity, has shown high sensitivity to detect mild structural alterations in multiple neurological disorders including PD (20). Though recent publications claimed very high diagnostic accuracy of reduced nigral FA values for PD patients (21), there have been several conflicting findings. Increased nigral FA values in PD patients were reported (22), but unchanged nigral FA values were also found in PD patients (23). Interestingly, in animal models of PD, their nigral FA values vary from elevated (24) to decreased (25). In our study, the results of increased FA values of SNc but not $\mathrm{SNr}$ of PD monkeys compared to controls might suggest the necessity of subregional research on SN with DTI. As decreased FA value represents increased diffusion of water molecules in the direction in which they are normally restricted, so it reflects microstructural modifications of SNc, such as nerve fibre impairment, demylination and cell loss. Results of our histochemical study are well in line with the known pathological changes in PD: early parkinsonian signs appear when SN has lost $70-80 \%$ of cells compared to the normal population (26). Unchanged FA values of $\mathrm{SNr}$ are somewhat in contradiction to the pathological features. Indeed, a large amount of TH positive neuron loss did occur in SN generally, which is supposed to cause decreased FA values of $\mathrm{SNr}$. Two possible explanations may be proposed: (i) the number of neurons lost in $\mathrm{SNr}$ could be insufficient to determine detectable regional abnormalities and (ii) the presence of gliosis and Lewy bodies might mask the micro-structural degradation induced by neuronal loss and reduce the diffusion of water molecules. Thus, it should be noted that combination of multiple neuroimaging measurements might provide greater diagnostic sensitivity in comparison to single measurements.

However, there are still some limitations of this study. Though several attempts have been made for the accurate iden- 
tification of the SN using MRI techniques, little could provide a clear discrimination between SNc and SNr (12). The manual ROI method we adopted might lack sufficient accuracy, so this study should be treated as a preliminary research. The future development of accurate methods for improved visualization on subregions of SN could be helpful for neuroimaging research of PD.

\section{CONCLUSION}

Combining the use of DTI and SWI can provide a sensitive method for differentiating between MPTP-induced rhesus monkey model of PD and wild-type controls. This effective imaging modality might provide additional information for characteristic identification of PD in the early stages, thus enhancing the ability to make early diagnosis, and monitor the progression of the natural history and treatment effects.

\section{ACKNOWLEDGMENTS}

This work is supported by the Scientific Research Foundation for Excellent Doctors of Xuzhou Medical College (D2014004) and National Natural Science Foundation of China (81200861).

\section{REFERENCES}

1. Goodarzi P, Aghayan HR, Larijani B, Soleimani M, Dehpour AR, Sahebjam $\mathrm{M}$ et al. Stem cell-based approach for the treatment of Parkinson's disease. Med J Islam Repub Iran 2015; 29: 168.

2. Meissner WG, Frasier M, Gasser T, Goetz CG, Lozano A, Piccini P et al. Priorities in Parkinson's disease research. Nat Rev Drug Discov 2011; 10: $377-93$.

3. Biundo R, Formento-Dojot P, Facchini S, Vallelunga A, Ghezzo L, Foscolo L et al. Brain volume changes in Parkinson's disease and their relationship with cognitive and behavioural abnormalities. J Neurol Sci 2011; 310: 64-9.

4. Pyatigorskaya N, Gallea C, Garcia-Lorenzo D, Vidailhet M, Lehericy S. A review of the use of magnetic resonance imaging in Parkinson's disease. Ther Adv Neurol Disord 2014; 7: 206-20.

5. Mittal S, Wu Z, Neelavalli J, Haacke EM. Susceptibility weighted imaging: technical aspects and clinical applications, part 2. AJNR Am J Neuroradiol 2009; 30: 232-52.

6. Meijer FJ, Goraj B. Brain MRI in Parkinson's disease. Front Biosci 2014; 6: 360-9.

7. Deng B, Zhang Y, Wang L, Peng K, Han L, Nie K. Diffusion tensor imaging reveals white matter changes associated with cognitive status in patients with Parkinson's disease. Am J Alzheimers Dis Other Demen 2013; 28: $154-64$.

8. Zhang Y, Wu IW, Buckley S, Coffey CS, Foster E, Mendick S et al. Diffusion tensor imaging of the nigrostriatal fibers in Parkinson's disease. Mov Disord 2015; 30: 1229-36.

9. Masilamoni GJ, Bogenpohl JW, Alagille D, Delevich K, Tamagnan G, Votaw JR et al. Metabotropic glutamate receptor 5 antagonist protects dopaminergic and noradrenergic neurons from degeneration in MPTPtreated monkeys. Brain 2011; 134: 2057-73.

10. Smith RD, Zhang Z, Kurlan R, McDermott M, Gash DM. Developing a stable bilateral model of parkinsonism in rhesus monkeys. Neuroscience 1993; 52: 7-16.

11. Roeltgen DP, Schneider JS. Chronic low-dose MPTP in nonhuman primates: a possible model for attention deficit disorder. J Child Neurol 1991; 6 (Suppl): S82-9.

12. Menke RA, Jbabdi S, Miller KL, Matthews PM, Zarei M. Connectivitybased segmentation of the substantia nigra in human and its implications in Parkinson's disease. Neuroimage 2010; 52: 1175-80.

13. Devergnas A, Pittard D, Bliwise D, Wichmann T. Relationship between oscillatory activity in the cortico-basal ganglia network and parkinsonism in MPTP-treated monkeys. Neurobiol Dis 2014; 68: 156-66.

14. Lin X, Shi M, Masilamoni JG, Dator R, Movius J, Aro P et al. Proteomic profiling in MPTP monkey model for early Parkinson disease biomarker discovery. Biochim Biophys Acta 2015; 1854: 779-87.

15. de Celis Alonso B, Hidalgo-Tobón SS, Menéndez-González M, SalasPacheco J, Arias-Carrión O. Magnetic resonance techniques applied to the diagnosis and treatment of Parkinson's disease. Front Neurol 2015; 6: 146.

16. Mahlknecht P, Hotter A, Hussl A, Esterhammer R, Schocke M, Seppi K. Significance of MRI in diagnosis and differential diagnosis of Parkinson's disease. Neurodegener Dis 2010; 7: 300-18.

17. Broski SM, Hunt CH, Johnson GB, Morreale RF, Lowe VJ, Peller PJ. Structural and functional imaging in parkinsonian syndromes. Radiographics 2014; 34: 1273-92.

18. Brooks DJ. Neuroimaging in Parkinson's disease: a future perspective. Neurodegener Dis Manag 2015; 5: 105-8.

19. Oikawa H, Sasaki M, Tamakawa Y, Ehara S, Tohyama K. The substantia nigra in Parkinson disease: proton density-weighted spin-echo and fast short inversion time inversion-recovery MR findings. AJNR Am J Neuroradiol 2002; 23: 1747-56.

20. Du G, Lewis MM, Sen S, Wang J, Shaffer ML, Styner M et al. Imaging nigral pathology and clinical progression in Parkinson's disease. Mov Disord 2012; 27: 1636-43.

21. Vaillancourt DE, Spraker MB, Prodoehl J, Abraham I, Corcos DM, Zhou $\mathrm{XJ}$ et al. High-resolution diffusion tensor imaging in the substantia nigra of de novo Parkinson disease. Neurology 2009; 72: 1378-84.

22. Wang JJ, Lin WY, Lu CS, Weng YH, Ng SH, Wang CH et al. Parkinson disease: diagnostic utility of diffusion kurtosis imaging. Radiology 2011; 261: $210-7$.

23. Focke NK, Helms G, Pantel PM, Scheewe S, Knauth M, Bachmann CG et al. Differentiation of typical and atypical Parkinson syndromes by quantitative MR imaging. AJNR Am J Neuroradiol 2011; 32: 2087-92.

24. Van Camp N, Blockx I, Verhoye M, Casteels C, Coun F, Leemans A et al. Diffusion tensor imaging in a rat model of Parkinson's disease after lesioning of the nigrostriatal tract. NMR Biomed 2009; 22: 697-706.

25. Soria G, Aguilar E, Tudela R, Mullol J, Planas AM, Marin C. In vivo magnetic resonance imaging characterization of bilateral structural changes in experimental Parkinson's disease: a T2 relaxometry study combined with longitudinal diffusion tensor imaging and manganese-enhanced magnetic resonance imaging in the 6-hydroxydopamine rat model. Eur J Neurosci 2011; 33: 1551-60.

26. Basser PJ, Pierpaoli C. Microstructural and physiological features of tissues elucidated by quantitative-diffusion-tensor MRI. J Magn Reson B 1996; 111: 209-19. 